DOI: $10.34220 /$ issn.2222-7962/2020.2/15

УДК $630 * 27$

КОНЦЕПЦИЯ СОЗДАНИЯ РЕКРЕАЦИОННЫХ ЗОН НА ПРИБРЕЖНЫХ ТЕРРИТОРИЯХ

\author{
кандидат сельскохозяйственных наук, доцент Н.П. Карташова \\ кандидат сельскохозяйственных наук, доцент М.Т. Сериков \\ кандидат сельскохозяйственных наук, старший преподаватель Е.Н. Кулакова \\ магистр лесного факультета Ю.Г. Астрелина \\ ФГБОУ ВО «Воронежский государственный лесотехнический университет имени Г.Ф. Морозова», \\ г. Воронеж, Российская Федерация
}

На фоне постоянного роста городов возрастают потребности населения в отдыхе, которые обусловили интенсивное рекреационное использование природных ландшафтов. Все большее число людей стремится удовлетворить потребности в отдыхе за пределами городской черты. Одними из таких объектов для отдыха являются прибрежные территории (прибрежные зоны), большинство которых не соответствует предъявляемым требованиям по их состоянию и благоустройству. Кроме того, такие зоны сильнее подвергаются техногенному воздействию, что способствует увеличению степени рекреационной дигрессии среды, деградации природных комплексов. Появляется необходимость в регулировании форм и способов использования природных ресурсов, что позволяет разработать систему экологичного их освоения, создавать благоприятные условия для отдыха, совершенствовать, поддерживать, эффективно использовать рекреационный потенциал природного комплекса. Объектом исследования послужили прибрежные территории реки Воронеж в селе Доброе Добровского района Липецкой области. Для обеспечения экологичного использования территории объекта исследования проведён расчет предельно допустимых рекреационных нагрузок, анализ ландшафтных показателей прибрежных территорий с выполнением их функционального рекреационного зонирования. Установлено, что для интенсификации использования прибрежных территорий необходимо выявлять принципы структуры их рекреационных пространств и планировочных решений. В результате исследований планируется осуществить анализ ряда факторов, которые оказывают влияние на организацию рекреационных функциональных зон в структуре прибрежных территорий села Доброе, позволяющий выявить проблемы и основные направления преобразования территории и раскрытия её потенциала. Рекомендован ассортимент растений для озеленения прибрежных территорий с учетом их устойчивости к данным условиям и антропогенным нагрузкам.

Ключевые слова: прибрежные территории, рекреационные функциональные зоны, биологическая устойчивость насаждений, ассортимент растений, озеленение, благоустройство 


\title{
CONCEPT OF RECREATIONAL ZONES CREATION IN RIVERFRONT TERRITORIES
}

\author{
$\mathrm{PhD}$ (Agriculture), Associate Professor N.P. Kartashova \\ $\mathrm{PhD}$ (Agriculture), Associate Professor M.T. Serikov \\ $\mathrm{PhD}$ (Agriculture), Senior Lecturer E.N. Kulakova \\ Master's degree student of Forestry Faculty Yu.G. Astrelina \\ FSBEI HE "Voronezh State University of Forestry and Technologies named after G.F. Morozov", \\ Voronezh, Russian Federation
}

\begin{abstract}
Against the backdrop of the constant city growth, the needs of the population for recreation are increasing. It has led to the intensive recreational use of natural landscapes. An increasing number of people are striving to meet the need for recreation outside the city limits. One of such objects for recreation is riverfront territories (coastal zones), most of which do not meet the requirements for their condition and improvement. In addition, such zones are more exposed to technogenic impact. It contributes to an increase in the degree of recreational digression of the environment and degradation of natural complexes. There is a need to regulate the forms and methods of using natural resources. It enables to develop a system for the environmentally friendly development of them, create favorable conditions for recreation, improve, maintain, and effectively use the recreational potential of the natural complex. The object of the study was the rivefront territories of the Voronezh River in the village of Dobroe, Dobrovsky district, Lipetsk region. Maximum permissible recreational loads have been calculated, the landscape indicators of the coastal territories have been analyzed with their functional recreational zoning performed to ensure the environmentally friendly use of the territory of the object of study. It is necessary to identify the principles of the structure of their recreational spaces and planning decisions in order to intensify the use of coastal territories. As a result of the research, it is planned to analyze a number of factors that influence the organization of recreational functional zones in the structure of the riverfront territories of the village of Dobroe. It enables to identify problems and the main directions for transforming the territory and revealing its potential. An assortment of plants for landscaping riverfront areas is recommended taking into account their resistance to these conditions and anthropogenic stress.
\end{abstract}

Keywords: riverfront territories, recreational functional areas, biological stability of plantations, assortment of plants, landscaping, redevelopment

\section{Введение}

В современных городах в связи с ростом урбанизации остро ощущается нехватка рекреационных зон. Сокращение городских насаждений и деградация растительности как в городе, так и в пригороде приводит к ухудшению экологической обстановки. Население сталкивается с проблемой нехватки рекреационных пространств, позволяющих удовлетворить потребность в повседневном и сезонном отдыхе. Проблема повышения качества систем рекреационного использования приобретает все большую актуальность по мере усложнения экономической ситуации. Зоны отдыха, расположенные в городских и пригородных районах, стали использоваться более интенсивно, что обусловило необходимость их развития. Прибрежные террито- рии являются именно такими рекреационными пространствами, которые массово используются для отдыха, особенно в теплое время года. Ухоженные территории речной долины, береговые линии с восстановленным растительным покровом и правильно подобранной растительностью являются резервом между урбанизированными территориями и водным объектом. При сохранении существующего природного потенциала прибрежных территорий, обеспеченных соответствующими мероприятиями по содержанию и эксплуатационным уходом, процессы дигрессии на этих территориях будут управляемы и стабилизированы. Поэтому в настоящее время при проведении ландшафтноэкологической оценки рекреационных зон нужно выявить комплекс методов, направленных на обес- 


\section{Ландшафтно-рекреационные насаждения}

печение устойчивости рекреационных функций в структуре прибрежных территорий. Необходимо выполнить комплексный анализ оценки данных территорий, который позволит выявить проблемы и факторы, влияющие на организацию отдыха на примере прибрежных территорий села Доброе. Также необходимо определить потенциал данных природных комплексов для создания туристскорекреационного кластера. Изучением прибрежных территорий занимались такие ученые, как М.Т. Сериков, В.М. Мишон, В.К. Тепляков, Л.М. Фурсова, В.А. Агальцова и др. [4]. Проблему использования населением прибрежных территорий для рекреационных целей можно считать актуальной, так как отдых у воды, особенно в летний период, пользуется повышенным спросом.

Для многоцелевого использования изучаемых территорий необходимо найти совершенно новый подход к решению проблемы сохранения прибрежных зон с повышением их экологической продуктивности, рекреационного потенциала и устойчивости, что определило направление проведенных исследований. Таким образом, назрела необходимость в разработке общей концепции создания рекреационных зон на прибрежных территориях.

\section{Материалы и методы}

Объектами исследования послужили прибрежные территории реки Воронеж села Доброе Добровского района Липецкой области, выполняющие множество функций (водорегулирующая, защитная, санитарно-гигиеническая), являясь одновременно одним из уникальнейших рекреационных объектов. Размещение туристическо-рекреационного кластера (ТРК) «Добрый» обусловлено наличием на его территории большого количества объектов, относящихся к объектам исторического и культурного наследия. В с. Панино - Ильинская церковь 1858 г. постройки, Спасская церковь 1838 г., усадьба князя Васильчикова XIX в. с. Трубетчино, Преображенская церковь 1901 г. в с. Гудово, Троицкая церковь 1880 г. в с. Большой Хомутец.

На территории, предназначенной для формирования туристского центра «Добрый», и в непосредственной близости от него расположены наи- более уникальные и ценные в природном, научном, культурном и эстетическом отношении природные комплексы. К ним относятся Добровский заповедник, Добровско-Филатовская пойма р. Воронеж, Мельников сад и т. д. Наличие таких объектов вызывают интерес не только у населения, проживающего в близлежащих населенных пунктах, но и у туристов, проезжающих транзитно из других городов. Чтобы привлечь большее количество отдыхающих, необходимо планировать создание туристско-рекреационного кластера «Добрый». Поэтому следует рекомендовать структуру организации рекреационной деятельности в прибрежной зоне северной части реки Воронеж села Доброе с учетом особенностей ландшафта, климата, с ориентацией на обеспечение сезонной устойчивости к антропогенным нагрузкам. В то же время рекреационное использование прибрежных территорий не должно привести к негативным последствиям, вызывающим деградацию среды, - вытаптыванию напочвенного покрова, уплотнению верхних почвенных горизонтов, гибели насаждений, загрязнению водоема. Поэтому необходимо провести исследования прибрежных территорий с назначением комплекса мероприятий, направленных на озеленение и благоустройство территории с повышением эстетических, санитарно-гигиенических и декоративных качеств как прибрежных, так и прилегающих территорий.

В настоящий момент ландшафтно-экологический анализ рассматривается как важнейший из методов изучения природно-экологического потенциала территории, включающий климатическую характеристику, оценку гидрологии и ресурсов поверхностных вод, рельеф и гидрогеологическое строение, физико-геологические процессы и инженерно-геологическую характеристику территории. Анализ градостроительной ситуации включает оценку экономической базы населённого пункта с его населением, культурно-бытовым обслуживанием, транспортной инфраструктурой и зеленым фондом. Для детального исследования территории применяется метод пофакторной оценки, базирующийся на оценке отдельных компонентов природной среды, что является рычагом в управлении качеством среды [2]. 
Используя действующие «Санитарные правила в лесах России», выделяют шесть категорий состояния насаждений (без признаков ослабления, ослабленные, сильно ослабленные, усыхающие, сухостой текущего года, сухостой прошлых лет $[6,8])$. По санитарно-гигиеническим факторам на территории объекта оцениваются микроклиматические и теллурические условия:

1) микроклиматические - оценка условий по температуре, влажности, ветровому режиму, солнечной радиации. Вместе эти данные должны обеспечить благоприятные условия для проживания человека;

2) теллурические - особенности состава воздуха, влияющие на организм, прежде всего, через дыхательные пути. Основную роль играет видовой состав древостоев, а также направление и повторяемость господствующих ветров. В зависимости от времени года и погоды показатели существенно меняются, они наиболее выражены в жаркие летние дни [1].

На основании наглядных и сравнительных выводов устанавливается эстетическая оценка территории $[1,5,6]$. Для обеспечения экологичного использования прибрежной территории рассчитывается максимально допустимая рекреационная нагрузка (Ен, чел.-дней). Использовалась методика, разработанная Всесоюзным научным центром медицинской реабилитации и физиотерапии, Т.Ф. Стойновым и Ю.В. Рысиным, а в дальнейшем доработанная М.Т. Сериковым [2, 3, 4].

Цель работы заключается в проведении анализа условий развития рекреационного потенциала села Доброе. Стояли задачи разработать научно обоснованный подход к ландшафтной организации рекреационных зон в структуре прибрежных территорий сельского поселения, а также рекомендовать ассортимент древесно-кустарниковой растительности под конкретные ландшафтные условия и рассчитать экономический эффект использования рекреационного ресурса.

Научная новизна исследования состоит в том, что впервые предложены принципы и методы ландшафтной организации рекреационных зон в структуре прибрежных территорий села Доброе Липецкой области, которые основываются на тре- бованиях качества среды с учетом рекреационной емкости. Апробированы методы качественной оценки привлекательности прибрежных территорий и методы количественной оценки рекреационных ресурсов. В качестве примера был предложен метод количественной оценки ресурсов пляжных территорий как наиболее значимых в условиях Липецкой области.

\section{Результаты исследований}

Насаждения на исследуемой территории здоровые, хорошего роста. Подрост, подлесочные породы, а также живой напочвенный покров хорошего качества, полностью покрывают почву. Здоровых деревьев в хвойных насаждениях не менее $90 \%$, а в лиственных - 70 \%. Поэтому по шкале оценки биологической устойчивости, разработанной в Московском лесотехническом институте МЛТИ, в основе которой лежит размер и характеристика текущего отпада [7], насаждения относятся к первому классу, у которых устойчивость не нарушена. Имеют место единичные поражения болезнями и вредителями, состояние среды не нарушено. Состояние насаждений соответствует хорошей категории, но процент озелененности ниже предъявляемой нормы - 20-40 \%. Ассортимент древесных пород также нуждается в дополнении, чтобы разнообразить прибрежные ландшафты и внести многоплановость в построение пейзажей. Поэтому необходимо применить в озеленении различные типы садово-парковых насаждений.

В ходе выполнения ландшафтно-экологической оценки объектов исследования получили следующие результаты: исследуемая территория относится к различным типам пространственной структуры: полуоткрытому с суммарной сомкнутостью полога с учетом подроста и подлеска не выше 0,5 и открытому, представленному полянами, дорогами и открытыми площадками.

Объект исследований, согласно санитарногигиенической оценке, имеет 1 (высший) класс [4], эстетическое качество оценено 37 баллами при максимальной оценке в 50 баллов [1]. Рекреационная оценка объекта достигла средней категории (второй), так как ландшафтные показатели объекта достаточно высокие. Отдельные компоненты комплекса требуют восстановительных мероприятий 


\section{Ландшафтно-рекреационные насаждения}

для улучшения условий отдыха. Элементы рекреационного благоустройства, достопримечательности были оценены в 2 балла из 15, так как имеющиеся ландшафтные поляны и водные пространства не содержат элементов благоустройства.

Прибрежные территории, которые могут быть использованы для отдыха населения у воды, нуждаются в дополнительном благоустройстве, а также озеленении. Это повысит комфортность отдыха, с одной стороны, и не приведет данные территории к деградации из-за снижения отрицательного экологического воздействия благодаря их благоустройству, с другой стороны. Для этого необходимо провести расчет предельно допустимых рекреационных нагрузок. Протяженность пляжной полосы на исследуемой территории в целом составила 3,5 км.

Данный пляж - песчаный. Курортологами доказано, что норматив предельно допустимой рекреационной нагрузки для песчаных пляжей морского побережья равен 3,5 чел.-дн./м - для одновременно отдыхавших в течение дня, на которых приходится 1 погонный метр пляжной полосы вдоль берега моря [4]. Для рассматриваемых условий реки Воронеж с учетом уровня психологической комфортности и санитарных норм этот норматив рекреационной емкости составляет 1,05 чел.-дн./м. Поэтому единовременно допустимая рекреационная нагрузка на исследуемой территории в целом 3675 чел.-дн.

Максимально возможная ежедневная посещаемость при среднем коэффициенте сменяемости 2 в разгар купального сезона достигает 7350 чел. в день, что может привести к деградации смежных с полосой пляжа элементов озеленения, поэтому необходимо планировать туристско-рекреационный кластер «Добрый» с благоустроенной и озелененной прибрежной территорией [10]. Предполагается, что стоимость одного посещения пляжа будет равна 10 рублям. Поэтому экономический эффект от использования пляжных рекреационных ресурсов в разгар купального сезона может достигать 73500 рублей в день, что экономически выгодно для сельских поселений.

Функциональное зонирование предлагаем осуществить с учетом проведенных исследований.
В результате выделяется «прибрежная зона отдыха», рекомендуемая ширина которой составит 40 м от уреза воды (соответствует ширине бечевника),

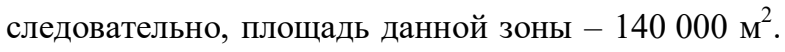
В пределах этой рекреационной функциональной зоны рекомендуем выделить «подзону пляжного отдыха», на которую отводится 50-70 \%, в среднем $55 \%$ (шириной 20-25 м от уреза воды). Площадь данной подзоны составит $77000 \mathrm{~m}^{2}$. Кластерно выделяем «подзону обслуживания», составляющую 10-18 \%, площадь которой будет 21000 м $^{2}$ (15\%), и «подзону детского отдыха» - 7-12\%, площадью 14000 м $^{2}(10 \%)$. «Подзона пляжного отдыха» наиболее посещаема и представляет собой открытое пространство с размещенными на ней раздевалками и необходимым для принятия солнечных ванн оборудованием. Затем параллельно берегу располагается наиболее удалённая от уреза воды «подзона активного отдыха», ширина которой может варьироваться от 10 до 30 м. Подзона менее посещаема по сравнению с пляжем, но требует более интенсивного благоустройства для преобладания дорожной формы рекреации со сниженной степенью отрицательного экологического воздействия на естественные природные элементы.

Озеленение прибрежной территории может составлять 20-40 \% от общей площади, на пешеходные дорожки и оборудованные площадки отдыха отводится 3-5 \%.

Таким образом, можно сделать вывод, что на территории села Доброе имеются условия и возможности для создания рекреационных территорий и их увеличения.

Озеленение является одним из методов, способствующих повышению качества, улучшению эстетических и декоративных свойств прибрежных территорий. Поэтому необходимо уделить особое внимание подбору ассортимента древесно-кустарниковой и травянистой растительности.

Таким образом, ассортимент древеснокустарниковой и почвопокровной растительности при озеленении рекреационных зон прибрежных районов реки Воронеж подобран, исходя из двух критериев $[3,8]$ :

- способность адаптации к климатическим факторам (подтоплениям); 
- высокие декоративные свойства.

На пойменных участках и районах с высоким уровнем грунтовых вод следует высаживать виды, устойчивые к длительному затоплению.

Созданные насаждения у водоема способны препятствовать испарению и интенсивному заилению, уменьшению эрозии почвы, что способствует увеличению срока службы водоема. В качестве кулис могут быть использованы одиночные посадки солитеры, которые направят взор отдыхающего на противоположный берег, а также внесут разнообразие в пейзаж. Создание полян как открытых типов пространственной структуры создаст необходимый фронт восприятия пейзажей, и они послужат местом отдыха населения.

В зоне пляжа, непосредственно у воды можно рекомендовать к посадке иву белую, ольху черную, которые могут выдержать затопление в течение 60 и более дней; тополь черный и белый, черёмуху обыкновенную, выдерживающие затопление в течение 40 дней; осину, вяз, выдерживающие затопление в течение 30 дней. Продвигаясь от водоема в сторону суши, ассортимент становится наиболее разнообразным. Здесь рекомендуются посадки дуба черешчатого и болотного, клена остролистного, липы мелколистной, ясеня обыкновенного и ели обыкновенной. Таким образом, непосредственно у воды рекомендуем одиночные посадки ивы белой, черемухи обыкновенной, вяза гладкого, которые также могут произрастать на выщелоченных черноземах и суглинистых почвах, характерных для данных условий. На расстоянии 20-40 м от воды можно рекомендовать посадку солитеров и ландшафтных групп, состоящих из трех-пяти экземпляров липа мелколистная, клен остролистный и черемуха обыкновенная; ива белая, клен остролистный и липа мелколистная. На границе «прибрежной зоны отдыха» можно рекомендовать рядовую посадку тополя черного, солитеры из ели обыкновенной, дуба черешчатого и болотного. В «подзоне активного отдыха» рекомендуем посадку солитеров из клена остролистного, липы мелколистной, березы повислой. Для озеленения дорожно-тропиночной сети рекомендуем живую изгородь из спиреи японской, жимолости Маака, кизильника блестящего, а также ландшафтные группы. Ландшафтная груп- па 1 состоит из барбариса оттавского, сосны горной, боярышника обыкновенного или ирги канадской, форзиции свисающей, свидины кровавокрасной. В ландшафтную группу 2 входят ель колючая, береза пушистая, ольха серая, ива, спирея. японская. Ландшафтная группа 3 состоит из клена остролистного, клена красного, свидины белой, форзиции свисающей, жимолости Маака, многолетников - гравилата гибридного, примулы.

Большинство растений способны сохранять свои декоративные свойства около одного-двух месяцев за вегетативный период. При выборе преобладающих древесно-кустарниковых пород упор был сделан на равномерное распределение функций доминирующих представителей за счет разницы в периодах фенологических фаз (цветение, плодоношение, смена окраски листьев) [9, 11, 12, 13]. Ассортимент растений представлен в посадочной ведомости (табл. 1).

Итоги табл. 1 показывают, что площадь озеленения под рекомендуемые посадки древеснокустарниковой растительности составит $4310 \mathrm{~m}^{2}$, что повысит степень озелененности прибрежной территории на 10 \%. Кроме того, необходимо устройство газона и цветочного оформления на видовых площадках, в результате чего степень озелененности достигнет нормативной. Для устройства газона на площади $800 \mathrm{~m}^{2}$ рекомендуем использовать газонную травосмесь "Dlf-trifolium" Golfmaster".

Благоустройство пляжа рекомендуется в расчете на 1 тысячу посетителей. Планируется разместить 80 м $^{2}$ теневых навесов, 1 контейнер, 5 мусорных баков, 3-4 торговых палатки [5]. В результате посещаемость пляжа в разгар купального сезона составит 7350 человек/день, при этом требуется $560 \mathrm{~m}^{2}$ теневых навесов, 7 контейнеров, 35 мусорных баков и 21 киоск. Также необходимым условием является устройство автостоянок, удаленность которых принимается в соответствии с санитарными нормами.

Рекомендуется предусматривать не менее 15-20 машино-мест на 100 единовременных посетителей пляжа $[1,5]$.

Таким образом, подбирая ассортимент растений для озеленения рекреационных пространств, 


\section{Ландшафтно-рекреационные насаждения}

неотъемлемым этапом при реализации различных приемов с использованием древесно-кустарниковой растительности является создание композиций, структурирование пространства, придание требуемых параметров и характера эстетической выразительности. Все принципы и приемы озеленения должны быть «привязаны» к водному объекту, составлять единую композицию. Озеленение и благо- устройство прибрежных территорий повысят качество отдыха, обеспечат сохранение природного ландшафта, а минимизация бездорожной и исключение автотранспортной форм рекреации за счёт благоустройства территории снизят степень отрицательного экологического воздействия рекреации и угрозу деградации природных комплексов.

Таблица 1

Посадочная ведомость

\begin{tabular}{|c|c|c|c|c|c|}
\hline \multirow{2}{*}{ № П/ா } & \multirow{2}{*}{ Ассортимент пород } & \multirow{2}{*}{$\begin{array}{c}\text { Площадь компонен- } \\
\text { та озеленения, м² }\end{array}$} & \multicolumn{2}{|c|}{ Количество растений, шт. } & \multirow{2}{*}{ Вид посадок } \\
\hline & & & Деревья & Кустарники & \\
\hline 1 & Береза повислая & 25 & 5 & & группа \\
\hline 2 & Ива белая & 32 & 8 & & солитер \\
\hline 3 & Дуб черешчатый & 39 & 8 & & солитер \\
\hline 4 & Ель колючая (Glauca) & 14 & 3 & & группа \\
\hline 5 & Дуб болотный & 30 & 6 & & солитер \\
\hline 6 & Вяз обыкновенный & 29 & 6 & & солитер \\
\hline 7 & Ель обыкновенная & 19 & 4 & & солитер \\
\hline 8 & Тополь черный & 99 & 25 & & рядовая \\
\hline 9 & Береза повислая & 28 & 7 & & солитер, группа \\
\hline 10 & $\begin{array}{l}\text { Клен остролистный } \\
\text { (Globosum) }\end{array}$ & 70 & 14 & & солитер, группа \\
\hline 11 & Черемуха Маака & 175 & 35 & & солитер, группа \\
\hline 12 & Липа мелколистная & 45 & 9 & & солитер, группа \\
\hline 13 & $\begin{array}{l}\text { Черемуха обыкно- } \\
\text { венная }\end{array}$ & 10 & 3 & & группа \\
\hline 14 & Клен красный & 12 & 2 & & группа \\
\hline 15 & Сосна горная & 13 & 2 & & группа \\
\hline 16 & Ольха серая & 73 & 15 & & группа \\
\hline 17 & $\begin{array}{l}\text { Ясень } \\
\text { ный }\end{array}$ & 60 & 12 & & солитер \\
\hline 18 & Ива остролистная & 10 & 2 & & группа \\
\hline 19 & Барбарис оттавский & 69 & & 70 & группа \\
\hline 20 & $\begin{array}{l}\text { Кизильник блестя- } \\
\text { щий }\end{array}$ & 1424 & & 1425 & живая изгородь \\
\hline 21 & Жимолость Маака & 1110 & & 1110 & живая изгородь \\
\hline 22 & Спирея японская & 850 & & 850 & живая изгородь \\
\hline 23 & $\begin{array}{l}\text { Боярышник обыкно- } \\
\text { венный }\end{array}$ & 20 & & 20 & группа \\
\hline 24 & Ирга канадская & 15 & & 15 & группа \\
\hline 25 & $\begin{array}{l}\text { Форзиция свисаю- } \\
\text { щая }\end{array}$ & 25 & & 25 & группа \\
\hline \multirow[t]{2}{*}{26} & Свидина белая & 10 & & 10 & группа \\
\hline & Итого & 4310 & 166 & 3525 & \\
\hline
\end{tabular}




\section{Выводы}

1. Оценивая комплекс факторов на исследуемом участке, его функциональное рекреационное зонирование выполнено с учетом оценки влияния экологических, природно-ландшафтных, климатических, социально-демографических факторов, в целом ориентировано на формирование устойчивой рекреационной функции в прибрежной зоне, функционально разнообразной, социально адаптированной и эстетически привлекательной среды.

2. Максимальная суточная посещаемость в разгар купального сезона, может достигать 7350 чел./сутки, что может привести к деградации прибрежных территорий, поэтому необходимо планировать туристско-рекреационный кластер «Добрый» с благоустроенной и озелененной прибрежной территорией.

3. Рассчитанный экономический эффект использования пляжно-купальных ресурсов в пик сезона может достигать 73500 рублей/день.

4. При подборе ассортимента древеснокустарниковой растительности необходимо обеспечивать его высокие декоративные свойства, устойчивость к особенностям климата, экологическим условиям, рекреационным нагрузкам.

5. Благоустройство прибрежных территорий должно выполняться по функциональным разностям, с учётом величины рекреационной емкости, посещаемости, степени экологической агрессивности преобладающих видов отдыха, что является главным инструментом регулирования рекреаци- онного использования на этих территориях, исключающего деградацию природного комплекса.

\section{Рекомендации}

1. Для регулирования рекреационного использования на прибрежных территориях реки Воронеж в селе Доброе рекомендуем комплексный анализ факторов с учетом специфики самого объекта и его расположения в планировочной структуре.

2. Рекомендуется функциональное зонирование с учетом особенностей исследуемой территории на основе выполненного ландшафтного анализа.

3. В предлагаемом ассортименте растений максимально учтены все особенности, а также предложены варианты типов садово-парковых насаждений, которые повысят эстетические, санитарно-гигиенические и декоративные свойства прибрежных территорий.

4. На прибрежных территориях хозяйственная деятельность должна быть направлена на максимальное сохранение существующих насаждений с повышением устойчивости, продуктивности, способствуя повышению их санитарно-гигиенических свойств. Учитывая рекреационное использование, необходимо провести учет насаждений с разными стадиями рекреационной дигрессии. При этом для участков насаждений 1-2 стадий, 2-3 стадий и 4 стадии должны быть разработаны отдельные комплексы хозяйственных мероприятий с учётом степени нарушения среды.

\section{Библиографический список}

1. Боговая, И. О. Ландшафтное искусство / И. О. Боговая, Л. М. Фурсова. - Москва : Агропромиздат, 1988. $-223 \mathrm{c}$.

2. Карташова, Н. П. Ландшафтно-экологическое обоснование рекреационного лесопользования в северной части зеленой зоны г. Воронежа : специальность 03.00 .16 «Экология» : дис. ... канд. с-х. наук : защищена 23.06.2003 / Карташова Нелли Павловна. - Воронеж, 2003. - 228 с.

3. Карташова, Н. П. Рекреационная емкость пляжных территорий и их благоустройство (на примере береговой линии реки Воронеж) / Н. П. Карташова, А. С. Селиванова // Известия Санкт-Петербургской лесотехнической академии. - 2016. - Вып. 217. - С. 638-642.

4. Сериков, М. Т. Основы лесоустройства рекреационных лесов : учеб. пособие / М. Т. Сериков, В. А. Бугаев, А. Н. Одинцов. - Воронеж : Воронеж. гос. лесотехн. акад., 2004. - 60 с.

5. Теодоронский, В. С. Объекты ландшафтной архитектуры : учеб. пособие для студентов спец. 260500 / В. С. Теодоронский, И. О. Боговая. - Москва : МГУЛ, 2003. - 330 с. 


\section{Ландшафтно-рекреационные насаждения}

6. О качественном и количественном аспектах оценки состояния растений в городских зеленых насаждениях / В. С. Теодоронский, Н. А. Авсиевич, В. А. Фролова, Х. Г. Якубов // Экология большого города. Проблемы содержания зеленых насаждений в условиях Москвы. Вып. 4. - Москва : Прима-Пресс-М, 2000. C. 29-37.

7. Тепляков, В. К. Ландшафтная таксация : учеб. пособие / В. К. Тепляков, Л. М. Фурсова, В. А. Агальцова. - Москва : МЛТИ, 1991. - 112 с.

8. Фирсова, Н. В. Эколого-градостроительный анализ состояния зеленых насаждений Воронежа / Н. В. Фирсова // Проблемы озеленения крупных городов. - Москва : Прима-М, 2005. - Вып. 11. - С. 69-71.

9. Bunio, L. V. Specific features of morphogenesis of sedge (Carex hirta L.) on oil-contaminated soil / L. V. Bunio, O. M. Tsvilynjuk // Contemporary Problems of Ecology. - 2015. - Vol. 8. - No. 5. - P. 660-667.

10. Kulakova, E.N. Forest plantations of the foot-hills of the North Caucasus and their environmental and economic assessment / E. N. Kulakova // International Scientific and Practical Conference "Forest Ecosystems as a Global Biosphere Resource: Challenges, Threats, Solutions. - Voronezh : VGLTU, 2019.

11. Galychyn, O. Organic Urbanism: Human-oriented Design for Metropolises / O. Galychyn, K. Ustundag // Procedia Environmental Sciences. - 2017. - P. 396-407.

12. Talovskaya (Kolegova), E. B. Thymus baicalensis (Lamiaceae) morphological transformation under different environmental conditions / E. B. Talovskaya (Kolegova) // Contemporary Problems of Ecology. - 2015. - Vol. 8. No. 5. - P. 607-613.

13. Turner, T. Open space planning in London / T. Turner // Strategic Planning Advice for London, October, 1988. - London, 1993. - P. 366-386.

\section{References}

1. Bogovaya I.O., Fursova L.M. Landshaftnoe iskusstvo [Landscape Design]. Moscow: Agropromizdat, 1988, 223 p. (in Russian).

2. Kartashova N.P. Landscape-ecological substantiation of recreational forest use in the northern part of the green zone of the city of Voronezh: PhD (Agriculture) thesis. Voronezh, 2003. 228 p. (in Russian).

3. Kartashova N.P., Selivanova A.S. (2016) Rekreatsionnaya emkost' plyazhnykh territoriy $i$ ikh blagoustroystvo (na primere beregovoy linii reki Voronezh) [Recreational capacity of beach territories and their improvement (on the example of the coastline of the river Voronezh)]. Izvestiya Sankt-Petersburgskoy lesotekhnicheskoy akademii. Iss. 217, pp. 638-642 (in Russian).

4. Serikov M.T. , bugaev V.A., Odintsov A.N. Osnovy lesoustrojstva rekreacionnyh lesov: ucheb. Posobie [Principles of recreational forestry: textbook]. Voronezh, 2004. 60 p. (in Russian).

5. Teodoronsky V.S., Bogovaya I.O. Ob'ekti landshaftnoi arkhitekturi [The objects of landscape architecture]. Moscow, 2003. 300 p. (in Russian).

6. Teodoronsky V.S., Avsievich N.A., Frolova V.A., Yakubov Kh.G. O kachestvennom i kolichestvennom aspektakh ocenki sostoyaniya rastenij $v$ gorodskikh zelenykh nasazhdeniyakh [About the qualitative and quantitative aspects of assessing the state of plants in urban green areas]. Ekologiya bolshogo goroda. Problemy soderzhaniya zelenykh nasazhdenij v usloviyakh Moskvy [Ecology of a big city. Problems of maintenance of green spaces in Moscow]. Moscow: Prima-Press-M, 2000, issue 4, pp. 29-37 (in Russian).

7. Teplyakov V.K., Fursova L.M., Agalzova V.A. Landshaftnaya taksatsiya: ucheb. posobie [Landscape taxation: textbook]. Moscow: MLTI, 1991. - 112 p. (in Russian).

8. Firsova N.V. Environmental and urban planning analysis of the state of green plantations in Voronezh. Problems of large cities landscaping. Moscow, Prima-M, 2005. vol. 11, pp. 69-71 (in Russian).

9. Bunio L.V., Tsvilynjuk O.M. (2015) Specific features of morphogenesis of sedge (Carex hirta L.) on oilcontaminated soil. Contemporary Problems of Ecology, vol. 8, no. 5, pp. 660-667. 
10. Kulakova E.N. Forest plantations of the foot-hills of the North Caucasus and their environmental and economic assessment. International Scientific and Practical Conference "Forest Ecosystems as a Global Biosphere Resource: Challenges, Threats, Solutions. Voronezh: VGLTU, 2019.

11. Galychyn O., Ustundag K. (2017) Organic Urbanism: Human-oriented Design for Metropolises. Procedia Environmental Sciences, pp. 396-407.

12. Talovskaya (Kolegova) E.B. (2015) Thymus baicalensis (Lamiaceae) morphological transformation under different environmental conditions. Contemporary Problems of Ecology, vol. 8, no. 5, pp. 607-613.

13. Turner T. Open space planning in London. Strategic Planning Advice for London, October, 1988. London, 1993. pp. 366-386.

\section{Сведения об авторах}

Карташова Нелли Павловна - кандидат сельскохозяйственных наук, доцент, доцент кафедры ландшафтной архитектуры и почвоведения ФГБОУ ВО «Воронежский государственный лесотехнический университет имени Г.Ф. Морозова», г. Воронеж, Российская Федерация; e-mail: Kartashova_73@mail.ru.

Сериков Михаил Тихонович - кандидат сельскохозяйственных наук, доцент, доцент кафедры лесоводства, лесной таксации и лесоустройства ФГБОУ ВО «Воронежский государственный лесотехнический университет имени Г.Ф. Морозова», г. Воронеж, Российская Федерация; e-mail: serikovmt@gmail.com.

Кулакова Екатерина Николаевна - кандидат сельскохозяйственных наук, старший преподаватель кафедры ландшафтной архитектуры и почвоведения ФГБОУ ВО «Воронежский государственный лесотехнический университет имени Г.Ф. Морозова», г. Воронеж, Российская Федерация; e-mail: kulakova_92@list.ru.

Астрелина Юлия Геннадьевна - магистр лесного факультета ФГБОУ ВО «Воронежский государственный лесотехнический университет имени Г.Ф. Морозова», г. Воронеж, Российская Федерация; е-mail: astrelinawork22@gmail.com.

\section{Information about authors}

Kartashova Nelly Pavlovna - PhD (Agriculture), Associate Professor of the Department of Landscape Architecture and Soil Science, FSBEI HE "Voronezh State University of Forestry and Technologies named after G.F. Morozov", Voronezh, Russian Federation; e-mail: Kartashova_73@mail.ru.

Serikov Mikhail Tikhonovich - PhD (Agriculture), Associate Professor of the Department of Forestry, Forest Taxation and Forest Management, FSBEI HE "Voronezh State University of Forestry and Technologies named after G.F. Morozov", Voronezh, Russian Federation; e-mail: serikovmt@gmail.com.

Kulakova Ekaterina Nikolaevna - PhD (Agriculture), Senior Lecturer of the Department of Landscape Architecture and Soil Science, FSBEI HE "Voronezh State University of Forestry and Technologies named after G.F. Morozov", Voronezh, Russian Federation; e-mail: kulakova_92@list.ru.

Astrelina Yulia Gennadyevna - Master's degree student of the Faculty of Forestry, FSBEI HE "Voronezh State University of Forestry and Technologies named after G.F. Morozov", Voronezh, Russian Federation; e-mail: astrelinawork22@gmail.com. 